\title{
Dissecting the molecular mechanism of nuclear receptor action: transcription coactivators and corepressors
}

\author{
Jae Woon Lee ${ }^{1,2,4}$, JaeHun Cheong, ${ }^{1,2}$, \\ Young Chul Lee ${ }^{1,2}$, Soon-Young $\mathrm{Na}^{1,3}$ \\ and Soo-Kyung Lee ${ }^{1,3}$ \\ ${ }^{1}$ Center for Ligand and Transcription
${ }^{2}$ Hormone Research Center
${ }^{3}$ Department of Biology, Chonnam National University,
Kwangju 500-757, Korea
${ }^{4}$ Corresponding author: Tel, +82-62-530-0910;
Fax, +82-62-530-0772; E-mail, jlee@ chonnam.chonnam.ac.kr
}

Accepted 21 June 2000

Abbreviations: HRE, hormone response elements; LBD, ligand binding domain; AF2, activation function; HAT, histone acetyl transferase; HDAC, deacetylase; CBP, CREB-binding protein; TRAPs, thyroid homone receptor associated proteins; VDR, vitamin $D_{3}$; ASC-1, activating signal cointegrator-1; RAR, retinoic acid receptor

Keywords: Nuclear receptor, transcription, coactivators, corepressors

\section{Introduction}

Over 150 members that belong to the nuclear receptor superfamily have been discovered since glucocorticoid receptor was first reported in 1985, which primarily regulate, in a ligand-dependent manner, transcriptional initiation of the target genes by directly binding to specific DNA sequences named hormone response elements (HRE) (reviewed in Mangelsdorf et al., 1995). The Cterminus of the ligand binding domain (LBD) of these proteins harbors an essential ligand-dependent transactivation function (activation function 2, AF2), whereas the N-terminus of many nuclear receptors often includes AF1. Genetic studies implicated that transcription cofactors with no specific DNA-binding activity are essential components of transcriptional regulation, which ultimately led to identify a series of nuclear receptor-interacting coregulatory proteins (reviewed in Horwitz et al., 1996). Thus far, these proteins have been shown to have a few characteristic features, as summarized in Figure 1. First, they bind to target transcription factors in a liganddependent manner. Second, many of them are capable of directly interacting with the basal transcriptional machinery. Third, some of them exhibit enzymatic function intrinsically linked to gene regulation, such as the nucleosomal remodeling histone acetyl transferase (HAT) or deacetylase (HDAC) activities. Thus, these proteins appear to function by either remodeling chromatin structures and/or acting as adapter molecules between nuclear receptors and the components of the basal transcriptional apparatus. Herein, we discuss the recent progress in studies of these coactivators and corepressors of nuclear receptors.

\section{The p160 Family}

A group of related proteins were found to enhance ligand-induced transactivation function of several nuclear receptors, named the p160 family. These proteins are grouped into three subclasses based on their sequence homology; i.e., SRC-1/NCoA-1 (Hong et al., 1997; Torchia et al., 1997; Voegel et al., 1998), TIF2/GRIP1/NCoA-2 (Hong et al., 1997; Voegel et al., 1998), and p/CIP/ ACTR/AIB1/xSRC-3 (Anzick et al., 1997; Chen et al., 1997; Kim et al., 1998; Torchia et al., 1997). A distinctive structural feature of the p160 coactivators is the presence of multiple LXXLL signature motifs (Heery et al., 1997; Torchia et al., 1997). The AF2 core (helix 12) was recently shown to undergo a major restructuring upon ligand binding, forming part of a "charged clamp" that accomodates p160 coactivators within a hydrophobic cleft of the receptor LBD, through direct contacts with these LXXLL motifs (Darimont et al., 1998; Nolte et al., 1998). Loss of function studies using antibody microinjection technique also suggested that the p160 family proteins are required for nuclear receptor functions in vivo (Torchia et al., 1997). In addition, these factors can also interact with CREB-binding protein (CBP)/p300 via a separate domain (Kamei et al., 1996; Yao et al., 1996). A weak intrinsic HAT activity has been reported in SRC1 and ACTR, suggesting that a function of these factor may involve chromatin remodeling (Chen et al., 1997; Spencer et al., 1997). We have recently shown that SRC-1 also mediates transactivation by a series of other transcription factors, including AP-1 (Lee et al., 1998), NFKB (Na et al., 1998), SRF (Kim et al., 1998a), and p53 (Lee et al., 1999). In particular, SRC-1 and p/CIP were strong coactivators for p53, whereas AIB1 and xSRC-3 were repressive (Lee et al., 1999). It is also noted that the p160 family of proteins has a number of uncharacterized isoforms (Chen et al., 1997; our unpublished results). These results suggest a provoking hypothesis that each member of the p160 family or isoforms may regulate a specific set of target transcription 


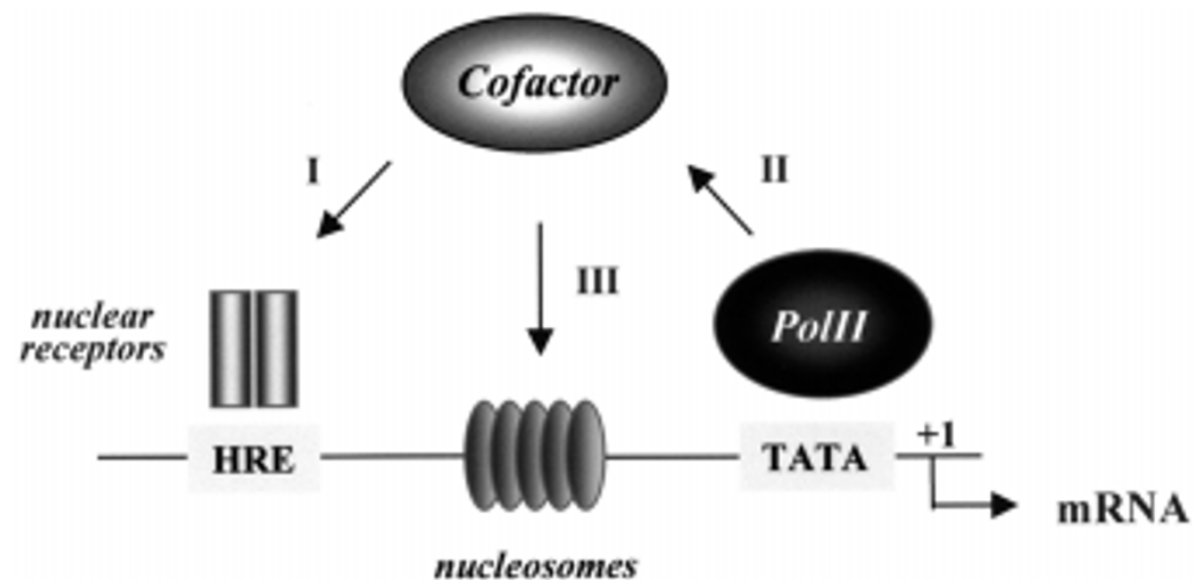

Figure 1. The role of transcriptional cofactors. Three general functions of known receptor cofactors are denoted as I, II, and III (see the text for details). HRE and +1 denote hormone response elements and transcription initiation site, respectively. Nuclear receptors, nucleosomes, cofactor and RNA polymerase II bound to TATA sequences are schematically depicted. Notably, RNA polymerase II and most cofactors exist as steady-state complex of multiple polypeptides, although each of them is represented as a single polypeptide for simplicity.

factors in vivo.

\section{CBP/p300}

CBP was originally isolated on the basis of its association with CREB in response to CAMP signaling, whereas its close homologue, p300, was purified as a cellular binding protein of the adenoviral protein E1A (Chrivia et al., 1993; Eckner et al., 1994). CBP and p300 have been implicated in functions of a large number of regulated transcription factors (reviewed in Goldman et al., 1997). For nuclear receptors, the interaction with CBP/ p300 is ligand- and AF2-dependent, although this direct interaction does not appear to be essential with many nuclear receptors (Westin et al., 1998; Li et al., 2000). In fibroblasts isolated from a $\mathrm{p} 300^{-/-}$mouse, however, RAdependent transcription was severely impaired, clearly indicating that $\mathrm{CBP} / \mathrm{p} 300$ are components of hormonal regulation of transcription in vivo (Yao et al., 1998). Surprisingly, CBP and p300 harbor HAT activity (Bannister et al., 1996; Ogryzko et al., 1996). In addition, purified p300 was shown to potentiate ligandinduced ER function only on chromatinized template, strongly indicating that a major function of CBP/p300 could be to modify chromatin structure via histone acetylation (Kraus and Kadonaga, 1998). However, it is notable that $\mathrm{CBP} / \mathrm{p} 300$ can also acetylate and functionally modulate, either in a negative or positive manner, non-histone proteins, including TFIIE $\beta$ (Imhof et al., 1997), p53 (Gu and Roeder, 1997), hematopoietic transcription factor GATA-1 (Boyes et al., 1998) and erythroid Krüppel-like factor (Zhang and Bieker, 1998). These results suggest that CBP/p300 may also target different aspects of gene activation, in addition to their roles in chromatin remodeling.

\section{p/CAF}

This protein was first discovered on the basis of sequence homology to the yeast HAT protein Gcn5p (Yang et al., 1996). The $\mathrm{N}$-terminus of $\mathrm{p} / \mathrm{CAF}$ interacts with CBP and members of the p160 family, whereas interaction interface between $\mathrm{p} / \mathrm{CAF}$ and nuclear receptors was different from that mediating the binding with either CBP/p300 or p160s (Blanco et al., 1998; Korzus et al., 1998). A core p/CAF complex was recently isolated by exploiting an affinity purification approach, which contained human homologues of the yeast ADA proteins, TAFs or TAF homologs, and p/CAF associated factor $65 \alpha$ which contains histone-like structure (Ogryzko et al., 1998). These results suggest a possible link between the $\mathrm{p} /$ CAF complex and the RNA polymerase II core machinery. This $\mathrm{p} / \mathrm{CAF}$ complex bears resemblance to the GCN5/SAGA complex in yeast. In particular, other subunits of the complex facilitate p/CAF to acetylate histones in the context of nucleosomes, although p/CAF alone is inert (Grant et al., 1997).

\section{TRAP/DRIP Complexes}

The thyroid hormone receptor associated proteins (TRAPs), composed of at least 9 polypeptides, were immunopurified from cells stably transfected with flag-tagged thyroid hormone receptors (Fondell et al., 1996). In reconstituted in vitro transcription assays utilizing naked DNA templates, the TRAP complex potentiated transactivation function of liganded TR. A highly homologous DRIP (vitamin $D_{3}$ receptor (VDR) interacting protein) complex was also isolated using VDR as the affinity matrix (Rachez et al., 1998), which substantially potentiated ligand-dependent transactivation function of VDR 
on a chromatinized template in vitro (Rachez et al., 1999). Interestingly, constituents of DRIP complex are almost identical to another newly discovered ARC (activator recruited cofactor) complex, which is essential for a number of other transcription factors such as SREBP, NFKB and VP16 (Naar et al., 1999; Rachez et al., 1999). This TRAP/DRIP complex is recruited to the LBD AF2 core in response to ligand-binding through a single subunit (DRIP205/TRAP220/TRIP2) via a single LXXLL motif (Lee et al., 1995; Naar et al., 1999; Rachez et al., 1999). This protein anchors the other components of the DRIP/TRAP complex to the receptor, thereby conferring hormone-dependent recruitment of what appears to be a preformed complex. In addition, TRAP/DRIP/ARC also contain part of the "Mediator complex" (Kim et al., 1994), strongly suggesting their direct connection to the RNA polymerase II core machinery.

\section{ASC-1}

We have recently discovered a novel nuclear receptorinteracting coactivator, termed activating signal cointegrator-1 (ASC-1) (Kim et al., 1999). ASC-1 harbors an autonomous transactivation function and binds to basal transcription factors TBP and TFIIA and transcription integrators SRC-1 and CBP/p300. The ASC-1 binding sites involve the hinge domain of nuclear receptors. Nonetheless, ASC-1 appears to require the AF2-dependent factors to function (i.e., CBP/p300 and SRC-1), as suggested by the ASC-1's ability to coactivate nuclear receptors, either alone or in conjunction with SRC-1 and p300, as well as its inability to coactivate a mutant receptor lacking the AF2 core region. The ASC-1-receptor bindings, a ligand-independent event in vitro when tested with purified components, are either ligand-dependent in vivo or become ligand-dependent in the presence of NCoR in vitro (Kim et al., 1999). Thus, ASC-1 may have more active roles in replacing NCoR/SMRT from receptors upon ligand binding. In addition, ASC-1, a nuclear protein, was found to be cytoplasmic under serum-deprivation but retained in nucleus when serumstarved in the presence of ligand or coexpressed CBP or SRC-1, suggesting additional roles for ASC-1 in cellular signal transductions (Kim et al., 1999). Recently, we have purified the steady-state ASC-1 complex from HeLa nuclei (our unpublished results), which consisted of four different polypeptides of 200, 100, 65 (ASC-1), and $50 \mathrm{kD}$. Isolation of their CDNAs revealed that P200 and P50 have multiple RNA-helicase domains and RNAbinding motifs, respectively. RNA helicase A was recently isolated as a transcriptional coactivator specific for the AF1 of estrogen receptor a (Endoh et al., 1999), whereas p68 RNA helicase was found to be a factor that mediates association of CBP with RNA polymerase II (Nakajima et al., 1997). Surprisingly, a novel transcrip- tional coactivator, p52, interacted not only with transcriptional activators and general transcription factors to enhance activated transcription but also with the essential splicing factor ASF/SF2 both in vitro and in vivo to modulate ASF/SF2-mediated pre-mRNA splicing (Ge and Wolfe, 1998). These results, along with the notion that pre-mRNA splicing can take place cotranscriptionally in vivo, suggest that, in addition to functioning as a transcriptional coactivator, ASC-1 may also act as an adaptor to coordinate pre-mRNA splicing and transcriptional activation of class II genes.

\section{ASC-2}

Activating signal cointegrator-2 (ASC-2) is another novel transcriptional coactivator molecule of nuclear receptors, recently isolated from this lab (Lee et al., 1999a). Similar or identical molecules were also reported by other groups, named TRBP (Ko et al., 2000), PRIP (Zhu et al., 2000), and RAP250 (Caira et al., 2000). ASC-2 harbors an autonomous transactivation function and binds to basal transcription factors TBP and TFIIA and transcription integrators SRC-1 and CBP/p300. Accordingly, ASC-2, a typical ligand- and AF2-dependent interactor of nuclear receptors, enhances the receptor transactivation, either alone or in conjunction with SRC-1 and p300. Interestingly, the autonomous transactivation domain of ASC-2 served as the interaction interface with CBP and the function of ASC-2 was absolutely dependent on the integrity of CBP recruitment in vivo (Lee et al., submitted). Consistent with an idea that ASC-2 is essential for the nuclear receptor function in vivo, microinjection of anti-ASC-2 antibody almost completely abrogated the ligand-dependent transactivation of retinoic acid receptor (RAR) (Lee et al., 1999a). More recently, we have also found that ASC-2 exists as a stable complex of multiple polypeptides in vivo (our unpublished results), which shows distinct chromatographic profiles from either ASC-1 (our unpublished results) or the recently described CBP/p300- and SRC-1-complexes (McKenna et al., 1998). In addition, the LXXLL-type receptor interaction domain of ASC-2 acted as a potent dominant negative mutant of the peroxisome proliferator-activated receptors (PPARs), RAR and TR transactivation (Zhu et al., 2000; Lee et al., submitted). These results suggested that ASC-2 should directly bind to receptors and recruit CBP to mediate the receptor transactivation in vivo. Surprisingly, ASC-2 was identical to AIB3, a gene previously identified during a search for genes amplified and overexpressed in breast and other human cancers (Guan et al., 1996). ASC-2 was recently found to mediate transactivation by a series of mitogenic transcription factors, including SRF, AP-1, NFKB and E2F (Lee et al., 2000; our unpublished results). Thus, ASC-2 may directly participate in the tumorigenesis processes when overex- 
pressed.

\section{NCOR/SMRT}

Unliganded-RAR and TR bind to their target genes and repress transcription. NCoR (Chen et al., 1995) and SMRT (Horlein et al., 1995) were originally isolated as factors associated with the hinge domain of these nuclear receptors in the absence of ligand. More recently, however, the molecular basis of NCoR/SMRT recruitment was shown to be similar to that of coactivator recruitment, involving cooperative binding of two helical interaction motifs within the NCoR carboxyl terminus to both subunits of an RAR-RXR heterodimer ( $\mathrm{Hu}$ and Lazar, 1999; Perissi et al., 1999). The NCoR/SMRT nuclear receptor interaction motifs exhibit a consensus sequence

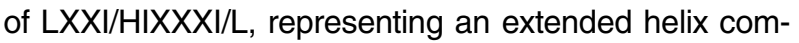
pared to the coactivator LXXLL helix (Heery et al., 1997; Torchia et al., 1997), which was able to interact with specific residues in the same receptor pocket required for coactivator binding. Thus, discrimination of the different lengths of the coactivator and corepressor interaction helices by the nuclear receptor AF2 motif may provide the molecular basis for the exchange of coactivators for corepressors, with ligand-dependent formation of the charge clamp that stabilizes LXXLL binding sterically inhibiting interaction of the extended corepressor helix. Interestingly, NCoR and SMRT harbor transferable repression domains and associate with HDAC, consistent with the concept that histone hypoacetylation correlates with gene repression (Heinzel et al., 1997; Nagy et al., 1997). Two groups have reported the isolation of HDAC core complexes (mSinA and the NuRD complex) that are critically involved in this transcriptional repression (Tong et al., 1998; Zhang et al., 1998). A few components of the NuRD complex are also present in the recently described Sin3 complex that consists of seven polypeptides (Laherty et al., 1998; Zhang et al., 1998a). In particular, SAP30 was found to directly interact with NCoR (Laherty et al., 1998). Antibody-blocking experiments and studies with HDAC inhibitors supported the idea that components of the NCoR/NuRD/mSin3 complex are required for repression mediated by these unliganded nuclear receptors. Thus, although NCoR doesn't appear to be stably associated with the mSin3 complex, it may serve as an adapter molecule between the core mSin3 complex and sequence-specific transcriptional repressors such as apo-nuclear receptors. Interestingly, the $\mathrm{N}-\mathrm{CoR} / \mathrm{Sin} 3 / \mathrm{HDAC}$ complex is also known to mediate transcriptional repression from a wide variety of other non-receptor-mediated pathways. These include AP-1, NFKB, SRF (Lee et al., 2000a), MyoD (Bailey et al., 1999), the bHLH-LZ proteins Mad and Mxi that mediate repression of myc activities and tumor suppression (Laherty et al., 1997), E2F-repressive retino- blastoma protein (Lai et al., 1999), and the oncoproteins PLZF-RAR (Lin et al., 1998) and LAZ3/BCL6 (Dhordain et al., 1997), which are involved in acute promyelocytic leukemia and non-Hodgkin lymphomas, respectively.

\section{Conclusion and Perspectives}

Transcription coactivators and corepressors provide important insights into the mechanisms by which ligand mediates the transactivation function of nuclear receptors. In brief, ligand binding results in the dismissal of HDAC-containing corepressor complexes and the concomitant recruitment of coactivator complexes. The current model for the coactivator recruitment by nuclear receptor involves two step mechanisms, as depicted in Figure 2A. First, SRC-1 appears to be directly recruited to the liganded-receptors, which then serves as a platform to recruit CBP. Consistent with this idea, the receptor-interacting $L X X L L$ motif located at the $\mathrm{N}$ terminus of CBP was deleted without significantly affecting transactivation by RAR-RXR heterodimers, whereas the SRC-1 LXXLL motifs were absolutely essential (Li et al., 2000; Westin et al., 1998). These factors and associated proteins such as p/CAF, by using their HAT activities, remodel the nucleosomal structures so that TRAP/DRIP complex can replace SRC-1/CBP and bind the liganded-receptors. Subsequent recruitment of RNA polymerase II complex to TRAP/DRIP completes the second step in the nuclear receptor transactivation. However, this simple view is blurred by a large number of other nuclear receptor binding cofactor proteins or complexes, in particular with the increasing number of AF2-dependent coactivators (Horwitz et al., 1996). Thus, one of the most immediate challenges to resolve is to unravel the inter-relationships between these distinct transcription cofactor proteins or complexes. These potential nuclear receptor cofactors may specifically function with different target genes as evidenced for CBP and p300 (Kawasaki et al., 1998). Alternatively, these complexes may sequentially engage in different steps during the ligandinduced transactivation by nuclear receptors. For instance, we have recently suggested that ASC-2 may play a similar, essential role as SRC-1; i.e. direct bindings to nuclear receptors and recruitment of CBP to the receptor-ASC-2 complex (Lee et al., submitted) (Figure 2B). Considering the fact that ASC-2 is expressed in relatively low amount in most cells but can be upregulated in certain cells by various cytokines and growth factors (our unpublished results), ASC-2 may serve as an inducible factor that represents an alternative functional homologue of SRC-1. It is also noted that, from the results with ASC-1 (Kim et al., 1999), RNA helicase A (Nakajima et al., 1997), p68 (Endoh et al., 1999), and p52 (Ge and Wolfe, 1998), transcription initiation was suggested to be directly 
(A)

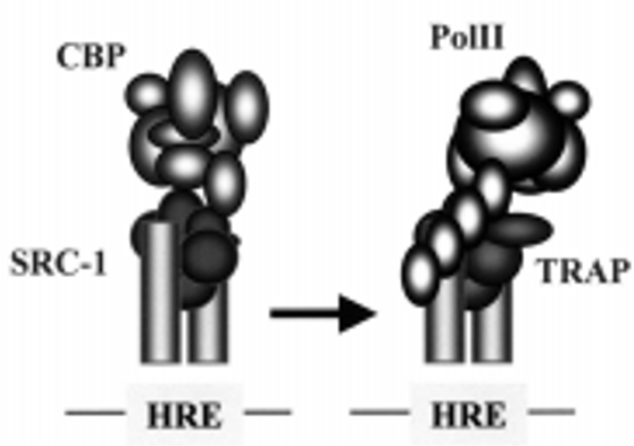

(B)

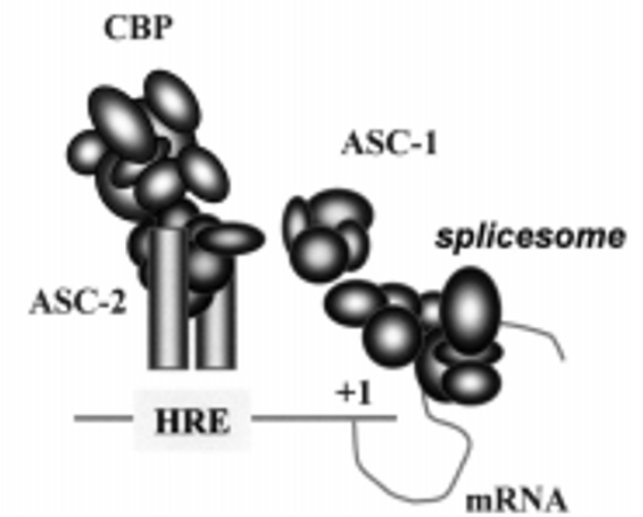

Figure 2. The model for the receptor function. (A) Two-step hypothesis for recruitment of coactivators is schematically explained, in which SRC-1 directly binds receptors and serves as a platform to recruit CBP. When CBP and associated proteins, using their HAT activities, remodel the nucleosomal structures, TRAP/ DRIP complex is suggested to occupy receptors and subsequently recruit the RNA polymerase II complex. (B) ASC-2 may act as an alternative, functional homologue of SRC-1, whereas ASC-1 may link pre-RNA splicings to transcriptional initiations (see the text for details).

linked to post-transcriptional RNA processing events (such as pre-RNA splicings, as depicted in Figure 2B). Finally, MAP kinase-induced phosphorylation of SRC-1 was recently demonstrated to enhance its ability to function as a transcriptional coactivator (Rowan et al., 2000), suggesting that signal transduction pathways may also modulate the assembly and/or functions of these cofactor complexes. Further characterization of these receptor coactivators and corepressors will undoubtedly unravel the fundamental mechanisms underlying the receptor function as well as the general transcription machinery.

\section{Acknowledgements}

We wish to thank other members of the Center for Ligand and Transcription for their valuable contributions to the studies described throughout this report. This work was exclusively supported from a grant awarded to J. W. L from the National Creative Research Initiatives Program of the Korean Ministry of Science and Technology.

\section{References}

Anzick, S. L., Kononen, J., Walker, R. L., Azorsa, D. O., Tanner, M. M., Guan, X. Y., Sauter, G., Kallioniemi, O. P., Trent, J. M. and Meltzer, P. S. (1997) AIB1, a steroid receptor coactivator amplified in breast and ovarian cancer. Science 277: 965-968

Bailey, P., Downes, M., Lau, P., Harris, J., Chen, S. L., Hamamori, Y., Sartorelli, V. and Muscat, G. E. (1999) The nuclear receptor corepressor $\mathrm{N}-\mathrm{CoR}$ regulates differentiation: $\mathrm{N}-\mathrm{CoR}$ directly interacts with MyoD. Mol. Endocrinol. 13:

\section{$1155-1168$}

Bannister, A. J. and Kouzarides, T. (1996) The CBP coactivator is a histone acetyltransferase. Nature 384: 641-643

Blanco, J. C. G., Minucci, S., Lu, J. M., Yang, X. J., Walker, K. K., Chen, H. W., Evans, R. M., Nakatani, Y. and Ozato, K. (1998) The histone acetylase PCAF is a nuclear receptor coactivator. Genes. Dev. 12: 1638-1651

Boyes, J., Byfield, P., Nakatani, Y. and Ogryzko, V. (1998) Regulation of activity of the transcription factor GATA-1 by acetylation. Nature 396: 594-598

Caira, F., Antonson, P., Pelto-Huikko, M., Treuter, E. and Gustafsson, J. A. (2000) Cloning and characterization of RAP250, a novel nuclear receptor coactivator. J. Biol. Chem. 275: $5308-5317$

Chen, J. D. and Evans, R. M. (1995) A transcriptional corepressor that interacts with nuclear hormone receptors. Nature 377: $454-457$

Chen, H. W., Lin, R. J., Schilz, R. L., Chakravarti, D., Nash, A., Nagy, L., Privalsky, M. L., Nakatani, Y. and Evans, R. M. (1997) Nuclear receptor coactivator ACTR is a novel histone acetyltransferase and forms a multimeric activation complex with P/CAF and CBP/p300. Cell 90: 569-580

Chrivia, J. C., Kwok, R. P. S., Lamb, N., Hagiwara, M., Montminy, M. R. and Goodman, R. H. (1993) Phosphorylated CREB binds specifically to the nuclear protein CBP. Nature 365: 855-859

Darimont, B. D., Wagner, R. L., Apriletti, J. W., Stallcup, M. R., Kushner, P. J., Baxter, J. D., Fletterick, R. J. and Yamamoto, K. R. (1998) Structure and specificity of nuclear receptorcoactivator interactions. Genes. Dev. 12: 3343-3356

Dhordain, P., Albagli, O., Lin, R. J., Ansieau, S., Quief, S., Leutz, A., Kerckaert, J. P., Evans, R. M. and Leprince, D. Corepressor SMRT binds the BTB/POZ repressing domain of the LAZ3/BCL6 oncoprotein. Proc. Natl. Acad. Sci. USA 94: 


\section{2-10767}

Eckner, R., Ewen, M. E., Newsome, D., Gerdes, M., DeCaprio, J. A., Lawrence, J. B. and Livingston, D. M. (1994) Molecular cloning and functional analysis of the adenovirus E1Aassociated 300-kd protein(p300) reveals a protein with properties of a transcriptional adaptor. Genes Dev. 8: 869-884

Endoh, H., Maruyama, K., Masuhiro, Y., Kobayashi, Y., Goto, M., Tai, H., Yanagisawa, J., Metzger, D., Hashimoto, S. and Kato, S. (1999) Purification and identification of p68 RNA helicase acting as a transcriptional coactivator specific for the activation function 1 of human estrogen receptor alpha. Mol. Cell. Biol. 19: 5363-5372

Fondell, J. D., Ge, H. and Roeder, R. G. (1996) Ligand induction of a transcriptionally active thyroid hormone receptor coactivator complex. Proc. Natl. Acad. Sci. USA 93: 83298333

Ge, H., Si, Y. and Wolffe, A. P. (1998) A novel transcriptional coactivator, p52, functionally interacts with the essential splicing factor ASF/SF2. Mol. Cell 2: 751-759

Goldman, P. S., Tran, V. K. and Goodman, R. H. (1997) The multifunctional role of the co-activator $\mathrm{CBP}$ in transcriptional regulation. Recent Prog. Horm. Res. 52: 103-120

Grant, P. A., Duggan, L., Cote, J., Roberts, S. M., Brownell, J. E., Candau, R., Ohba, R., Owen-Hughes, T., Allis, C. D., Winston, F., Berger, S. L. and Workman, J. L. (1997) Yeast Gcn5 functions in two multisubunit complexes to acetylate nucleosomal histones: characterization of an Ada complex and the SAGA (Spt/Ada) complex. Genes Dev. 11: 1640-1650

Gu, W. and Roeder, R. G. (1997) Activation of p53 sequencespecific DNA binding by acetylation of the p53 C-terminal domain. Cell 90: 595-606

Guan, X. Y., Xu, J., Anzick, S. L., Zhang, H., Trent, J. M. and Meltzer, P. S. (1996) Hybrid selection of transcribed sequences from microdissected DNA: isolation of genes within amplified region at 20q11-q13.2 in breast cancer. Cancer Res. 56: $3446-3450$

Heery, D. M., Kalkhoven, E., Hoare, S. and Parker, M. G. (1997) A signature motif in transcriptional co-activators mediates binding to nuclear receptors. Nature 387: 733-736

Heinzel, T., Lavinsky, R. M., Mullen, T. M., Soderstrom, M., Laherty, C. D., Torchia, J., Yang, W. M., Brard, G., Ngo, S. D., Davie, J. R., Seto, E., Eisenman, R. N., Rose, D. W., Glass, C. K. and Rosenfeld, M. G. (1997) A complex containing N$\mathrm{CoR}, \mathrm{mSin} 3$ and histone deacetylase mediates transcriptional repression. Nature 387: 43-48

Hong, H., Koli, K., Garbedian, M. J. and Stallcup, M. R. (1997) GRIP1, a transcriptional coactivator for the AF-2 transactivation domain of steroid, thyroid, retinoid, and vitamin D receptors. Mol. Cell. Biol. 17: 2735-2744

Horlein, A. J., Naar, A. M., Heinzel, T., Torchia, J., Gloss, B., Kurokawa, R., Ryan, A., Kamei, Y., Soderstrom, M., Glass, C. K. and Rosenfeld, M. G. (1995) Ligand-independent repression by the thyroid hormone receptor mediated by a nuclear receptor corepressor. Nature 377: 397-404

Horwitz, K. B., Jackson, T. A., Bain, D. L., Richer, J. K.,
Takimoto, G. S. and Tung, L. (1996) Nuclear receptor coactivators and corepressors. Mol. Endocrinol. 10: 1167-1177

Hu, X. and Lazar, M. A. (1999) The CoRNR motif controls the recruitment of corepressors by nuclear hormone receptors. Nature 402: 93-96

Imhof, A., Yang, X. J., Ogryzko, V. V., Nakatani, Y., Wolffe, A. P. and $\mathrm{Ge}, \mathrm{H}$. (1997) Acetylation of general transcription factors by histone acetyltransferases. Curr. Biol. 7: 689-692

Kamei, Y., Xu, L., Heinzel, T., Torchia, J., Kurokawa, R., Gloss, B., Lin, S. C., Heyman, R. A., Rose, D. W., Glass, C. K. and Rosenfeld, M. G. (1996) A CBP integrator complex mediates transcriptional activation and AP-1 inhibition by nuclear receptors. Cell 85: 403-414

Kawasaki, H., Eckner, R., Yao, T. P., Taira, K., Chiu, R., Livingston, D. M. and Yokoyama, K. K. (1998) Distinct roles of the co-activators p300 and CBP in retinoic-acid-induced F9cell differentiation. Nature 393: 284-289

Kim, Y. J., Bjorklund, S., Li, Y., Sayre, M. H. and Kornberg, R. D. (1994) A multiprotein mediator of transcriptional activation and its interaction with the C-terminal repeat domain of RNA polymerase II. Cell 77: 599-608

Kim, H. J., Lee, S. K., Na, S. Y., Choi, H. S. and Lee, J. W. (1998) Molecular cloning of xSRC-3, a novel transcription coactivator from Xenopus, that is related to AIB1, p/CIP, and TIF2. Mol. Endocrinol. 12: 1038-1047

Kim, H. J., Kim, J. H. and Lee, J. W. (1998a) Steroid receptor coactivator-1 interacts with serum response factor and coactivates serum response element-mediated transactivations. J. Biol. Chem. 273: 28564-28567

Kim, H. J., Yi, J. Y., Sung, H. S., Moore, D. D., Jhun, B. H., Lee, Y. C. and Lee, J. W. (1999) ASC-1, as a novel transcription coactivator of nuclear receptors, and its cytosolic localization under serum-deprivation. Mol. Cell. Biol., in press.

Ko, L., Cardona, G. R. and Chin, W. W. (2000) Thyroid hormone receptor-binding protein, an LXXLL motif-containing protein, functions as a general coactivator. Proc. Natl. Acad. Sci. USA 97: 6212-6217

Korzus, E., Torchia, J., Rose, D. W., Xu, L., Kurokawa, R., Mclnerney, E. M., Mullen, T. M., Glass, C. K. and Rosenfeld, M. G. (1998) Transcription factor-specific requirements for coactivators and their acetyltransferase functions. Science 279: 703-707

Kraus, W. L. and Kadonaga, J. T. (1998) p300 and estrogen receptor cooperatively activate transcription via differential enhancement of initiation and reinitiation. Genes Dev. 12: 331342

Laherty, C. D., Billin, A. N., Lavinsky, R. M., Yochum, G. S., Bush, A. C., Sun, J. M., Mullen, T. M., Davie, J. R., Rose, D. W., Glass, C. K., Rosenfeld, M. G., Ayer, D. E. and Eisenman, R. N. (1998) SAP30, a component of the mSin3 corepressor complex involved in N-CoR-mediated repression by specific transcripgion factors. Mol. Cell 2: 33-42

Laherty, C. D., Yang, W. M., Sun, J. M., Davie, J. R., Seto, E. and Eisenman, R. N. (1997) Histone deacetylases associated 
with the mSin3 corepressor mediate mad transcriptional repression. Cell 89: 349-356

Lai, A., Lee, J. M., Yang, W. M., DeCaprio, J. A., Kaelin, W. G. Jr., Seto, E. and Branton, P. E. (1999) RBP1 recruits both histone deacetylase-dependent and -independent repression activities to retinoblastoma family proteins. Mol. Cell. Biol. 19: 6632-6641

Lee, J. W., Choi, H. S., Gyuris, J., Brent, R. and Moore, D. D. (1995) Two classes of proteins dependent on either the presence or absence of thyroid hormone for interaction with the thyroid hormone receptor. Mol. Endocrinol. 9: 243-254

Lee, S. K., Kim, H. J., Na, S. Y., Kim, T. S., Choi, H. S., Im, S. Y. and Lee, J. W. (1998) Steroid receptor coactivator-1 coactivates activating protein-1-mediated transactivations through interaction with the c-Jun and c-Fos subunits. J. Biol. Chem. 273: 16651-16654

Lee, S. K., Kim, H. J. and Lee, J. W. (1999) SRC-1 and its family members differentially regulate transactivation by the tumor suppressor p53. Mol. Endocrinol. 13: 1924-1933

Lee, S. K., Anzick, S. L., Choi, J. E., Bubendorf, L., Guan, X. Y., Jung, Y. K., Kallioniemi, O. P., Kononen, J., Trent, J. M., Azorsa, D., Jhun, B. H., Meltzer, P. S. and Lee, J. W. (1999a) ASC-2, a novel transcriptional coactivator of nuclear receptors and its amplification in human cancers. J. Biol. Chem. 274: 34283-34293

Lee, S.-K., Na, S.-Y., Jung, S.-Y., Jhun, B. H., Cheong, J. H., Meltzer, P. S., Lee, Y. C. and Lee, J. W. (2000) Activating protein-1, nuclear factor- $\mathrm{\kappa} B$ and serum response factor, as novel target molecules of the cancer-amplified transcription coactivator ASC-2. Mol. Endocrinol. 14: 915-925

Lee, S.-K., Kim, J.-H., Lee, Y. C., Cheong, J. and Lee, J. W. (2000a) Silencing mediator of retinoic acid and thyroid hormone receptors, as a novel transcriptional corepressor molecule of activating protein-1, nuclear factor- $\mathrm{KB}$ and serum response factor. J. Biol. Chem. 275: 12470-12474

Lee, S-.K., Jung, S-.Y., Na, S-.Y., Cheong, J., Lee, Y. C. and Lee, J. W. Two Distinct Nuclear Receptor-Interaction Domains and CREB-Binding Protein-Dependent Transactivation Function of Activating Signal Cointegrator-2. Mol. Endocrinol., submitted.

Li, Y., Bjorklund, S., Jiang, Y. W., Kim, Y. J., Lane, W. S., Stillman, D. J. and Kornberg, R. D. (1995) Yeast global transcriptional regulators $\operatorname{Sin} 4$ and Rgr1 are components of mediator complex/RNA polymerase II holoenzyme. Proc. Natl. Acad. Sci. USA 92: 10864-10868

Li, J., O'Malley, B. W. and Wong, J. (2000) p300 requires its histone acetyltransferase activity and SRC-1 interaction domain to facilitate thyroid hormone receptor activation in chromatin. Mol. Cell. Biol. 20: 2031-2042

Lin, R. J., Nagy, L., Inoue, S., Shao, W., Miller, W. H. Jr. and Evans, R. M. (1998) Role of the histone deacetylase complex in acute promyelocytic leukaemia. Nature 391: 811-814

Mangelsdorf, D. J., Thummel, C., Beato, M., Herrlich, P., Schutz, G., Umesono, K., Blumberg, B., Kastner, P., Mark, M., Chambon, P. and Evans, R. M. (1995). The nuclear receptor superfamily: the second decade. Cell 83: 835-839

McKenna, N. J., Nawaz, Z., Tsai, S. Y., Tsai, M. J. and O'Malley, B. W. (1998) Distinct steady-state nuclear receptor coregulator complexes exist in vivo. Proc. Natl. Acad. Sci. USA 95: 11697-11702

Munshi, N., Merika, M., Yie, J., Senger, K., Chen, G. and Thanos, D. (1998) Acetylation of HMG I(Y) by CBP turns off IFN beta expression by disrupting the enhanceosome. Mol. Cell. 2: $457-467$

Na, S. Y., Lee, S. K., Han, S. J., Choi, H. S., Im, S. Y. and Lee, J. W. (1998) Steroid receptor coactivator-1 interacts with the p50 subunit and coactivates nuclear factor $\kappa \mathrm{B}$-mediated transactivations. J. Biol. Chem. 273: 10831-10834

Naar, A. M., Beaurang, P. A., Zhou, S., Abraham, S., Solomon, W. and Tjian, R. (1999) Composite co-activator ARC mediates chromatin-directed transcriptional activation. Nature 398: 828832

Nagy, L., Kao, H.-Y., Chakravarti, D., Lin, R. J., Hassig, C. A., Ayer, D. E., Schreiber, S. L. and Evans, R. M. (1997) Nuclear receptor repression mediated by a complex containing SMRT, mSin3A, and histone deacetylase. Cell 89: $373-380$

Nakajima, T., Uchida, C., Anderson, S. F, Lee, C. G., Hurwitz, J., Parvin, J. D. and Montminy, M. (1997) RNA helicase A mediates association of CBP with RNA polymerase II. Cell 90: 1107-1112

Nolte, R. T., Wisely, G. B., Westin, S., Cobb, J. E., Lambert, M. H., Kurokawa, R., Rosenfeld, M. G., Willson, T. M., Glass, C. K. and Milburn, M. V. (1998) Ligand binding and coactivator assembly of the peroxisome proliferator-activated receptor-gamma. Nature 395: 137-143

Ogryzko, V. V., Schiltz, R. L., Russanova, V., Howard, B. H. and Nakatani, Y. (1996) The transcriptional coactivators p300 and CBP are histone acetyltransferases. Cell 87: 953-959

Ogryzko, V. V., Kotani, T., Zhang, X., Schlitz, R. L., Howard, T., Yang, X. J., Howard, B. H., Qin, J. and Nakatani, Y. (1998) Histone-like TAFs within the PCAF histone acetylase complex. Cell 94: 35-44

Perissi, V., Staszewski, L. M., McInerney, E. M., Kurokawa, R., Krones, A., Rose, D. W., Lambert, M. H., Milburn, M. V., Glass, C. K. and Rosenfeld, M. G. (1999) Molecular determinants of nuclear receptor-corepressor interaction. Genes Dev. 13: 3198-3208

Rachez, C., Suldan, Z., Ward, J., Chang, C. P., Burakov, D., Erdjument-Bromage, H., Tempst, P. and Freedman, L. P. (1998) A novel protein complex that interacts with the vitamin D3 receptor in a ligand-dependent manner and enhances VDR transactivation in a cell-free system. Genes Dev. 12: 1787-1800

Rachez, C., Lemon, B. D., Suldan, Z., Bromleigh, V., Gamble, M., Naar, A. M., Erdjument-Bromage, H., Tempst, P. and Freedman, L. P. (1999) Ligand-dependent transcription activation by nuclear receptors requires the DRIP complex. Nature 398: 824-828

Rowan, B. G., Weigel, N. L. and O'Malley, B. W. (2000) Phosphorylation of steroid receptor coactivator-1. Identification of 
the phosphorylation sites and phosphorylation through the mitogen-activated protein kinase pathway. J. Biol. Chem. 275: 4475-4483

Spencer, T. E., Jenster, G., Burcin, M. M., Allis, C. D., Zhou, J. X., Mizzen, C. A., McKenna, N. J., Onate, S. A., Tsai, S. Y., Tsai, M. J. and O'Malley, B. W. (1997) Steroid receptor coactivator-1 is a histone acetyltransferase. Nature 389: 194-198

Tong, J. K., Hassig, C. A., Schnitzler, G. R., Kingston, R. E. and Schreiber, S. L. (1998) Chromatin deacetylation by an ATP-dependent nucleosome remodelling complex. Nature 395: 917-921

Torchia, J., Rose, D. W., Inostroza, J., Kamei, Y., Westin, S., Glass, C. K. and Rosenfeld, M. G. (1997) The transcriptional co-activator $\mathrm{p} / \mathrm{CIP}$ binds CBP and mediates nuclear-receptor function. Nature 387: 677-684

Voegel, J. J., Heine, M. J. S., Tini, M., Vivat, V., Chambon, P. and Gronemeyer, H. (1998) The coactivator TIF2 contains three nuclear receptor-binding motifs and mediates transactivation through $\mathrm{CBP}$ binding-dependent and -independent pathways. EMBO J. 17: 507-519

Westin, S., Kurokawa, R., Nolte, R. T., Wisely, G. B., McInerney, E. M., Rose, D. W., Milburn, M. V., Rosenfeld, M. G. and Glass, C. K. (1998) Interactions controlling the assembly of nuclear-receptor heterodimers and co-activators. Nature 395: 199-202

Yang, X. J., Ogryzko, V. V., Nishikawa, J., Howard, B. H. and Nakatani, Y. (1996) A p300/CBP-associated factor that competes with the adenoviral oncoprotein E1a. Nature 382: 319-
324

Yao, T. P., Ku, G., Zhou, N., Scully, R. and Livingston, D. M. (1996). The nuclear hormone receptor coactivator SRC-1 is a specific target of p300. Proc. Natl. Acad. Sci. USA 93: 1062610631

Yao, T. P., Oh, S. P., Fuchs, M., Zhou, N. D., Ch'ng, L. E., Newsome, D., Bronson, R. T., Li, E., Livingston, D. M. and Eckner, R. (1998) Gene dosage-dependent embryonic development and proliferation defects in mice lacking the transcriptional integrator p300. Cell 93: 361-372

Zhang, Y., LeRoy, G., Seelig, H. P., Lane, W. S. and Reinberg, D. (1998) The dermatomyositis-specific autoantigen Mi2 is a component of a complex containing histone deacetylase and nucleosome remodeling activities. Cell 95: 279-289

Zhang, Y., Sun, Z. W., Iratni, R., Erdjument-Bromage, H., Tempst, P., Hampsey, M. and Reinberg, D. (1998a) SAP30, a novel protein conserved between human and yeast, is a component of a histone deacetylase complex. Mol. Cell. 1: 1021-1031

Zhang, W. and Bieker, J. J. (1998) Acetylation and modulation of erythroid Kruppel-like factor (EKLF) activity by interaction with histone acetyltransferases. Proc. Natl. Acad. Sci. USA 95: 9855-9860

Zhu, Y., Kan, L., Qi, C., Kanwar, Y. S., Yeldandi, A. V., Rao, M. S. and Reddy, J. K. (2000) Isolation and characterization of peroxisome proliferator-activated receptor (PPAR) interacting protein (PRIP) as a coactivator for PPAR. J. Biol. Chem. 275: 13510-13516 